\title{
Developing a Meta-Model of Critical Factors for Females in STEM with Application to a Minority-serving Institution
}

\section{Dr. Lourdes A. Medina, University of Puerto Rico at Mayaguez}

Dr. Lourdes A. Medina is an Associate Professor from the Department of Industrial Engineering (IE) at the University of Puerto Rico at Mayaguez. Dr. Medina has made great contributions to recruitment of minorities in engineering through her RealTimePC outreach initiative since 2013. Passionate about developing the next generation of engineers, Dr. Medina created the IDDEAS Research Group. Current research activities are mainly focused on Engineering Education from the perspective of outreach to minorities with focus on women recruitment, retention and progression. Other research activities include: systems and product design, decision analysis, manufacturing, process automation and real-time process control. Dr. Medina is currently appointed as President (2019-2021) of the Manufacturing and Design Division for the Institute of Industrial and Systems Engineers (IISE). Dr. Medina has received multiple recognitions for her work that include the IISE M\&D Outstanding Service Award (2016), UPRM Recognition on the 4th Research Academy for Faculty \& Postdoctoral Fellowships Symposium (2015-2016), CIAPR Emergent Leader (2015) and UPRM Industrial Engineering Outstanding Professor (2014-2015).

\section{Dr. Saylisse Davila, University of Puerto Rico-Mayaguez}

Saylisse Dávila is a Professor in the Department of Industrial Engineering at University of Puerto RicoMayagüez. She holds $\mathrm{PhD}$ and MSE degrees in Industrial Engineering from Arizona State University, and a BS in Industrial Engineering from University of Puerto Rico-Mayagüez. Her teaching interests include probability, statistics, and machine learning; while, her research interests include method development and data-driven applications in statistical learning. In recent years, her applied work focus has geared towards natural hazards and engineering education.

\section{Miss Olga Beatriz Rivera, Amgen Manufacturing Limited}

Bachelor's degree from Department of Industrial Engineering at University of Puerto Rico at Mayaguez. Industrial Engineer in Amgen Manufacturing Limited at Operational Excellence Department.Pursuing a Master degree in Supply Chain \& Material Management.

\section{Nolgie Oquendo-Colon, University of Puerto Rico, Mayaguez Campus}

Nolgie Oquendo is a Graduate Student (MSE) in the Department of Industrial Engineering at the University of Puerto Rico-Mayaguiez. He holds a BS in Industrial Engineering from the University of Puerto Rico at Mayaguez. He is seeking to pursue a PhD in Engineering Education. Research interests include Diversity and Inclusion, Design and Evaluation, and Data Analytics.

\section{Dr. Maria Angelica Velazquez, Montana State University}

Dr. Velazquez is a faculty member at the Mechanical and Industrial Engineering Department at Montana State University. She is also faculty support in the Empower program for underrepresented minority students in STEM fields. She has a PhD. in Industrial and Manufacturing Systems Engineering from The Pennsylvania State University. Dr. Velazquez is interested in research related to recruitment, retention, and success of minority students in STEM, and she is passionate about topics related to increasing the participation of women in Engineering. 


\title{
Developing a Meta-Model of Critical Factors for Females in STEM with Application to a Minority-serving Institution
}

\begin{abstract}
Over recent decades, federal and private organizations efforts to fund females-centered projects have paved the way to a vast array of empirical studies aimed at the advancement of females. For the most part, these studies assess the conditions for females in terms of their recruitment, retention, and progression in undergraduate/graduate studies or faculty positions. These studies conclude with the proposition of policies and practices that are intended to help transform institutions favorably for females. However, while large investments are done to change this paradigm, females in this era still face discrimination and are treated unfairly in many different settings. New and innovative methods are needed for transcendental changes; therefore, we take a step back to the identification of critical factors for females in STEM. To propose solutions, we must understand the issues first. This paper presents the creation of a conceptual model as an advocate to complexity thinking in problem solving. The development of the model involved the review of relevant literature from two viewpoints- an undergraduate female/Hispanic student and a tenure-track female/Hispanic professor. From these analyses, two models were generated and, lastly, a meta-model was built merging these models. We propose a hierarchical model in which factors are categorized as personal/individual, institutional, external, and sociocultural. The relevance of these factors to female's recruitment, retention, and progression is presented along with their positive or negative impact. Finally, the model was revised once more to incorporate the results of an ADVANCE program carried out at a minority-serving institution.
\end{abstract}

\section{Introduction}

While females around the world continue to advance to leadership roles, they still face discrimination and are treated unfairly in many different settings; particularly, the ones in Science, Technology, Engineering and Math (STEM) education. Females in STEM are mostly underrepresented and constantly face recruitment and retention issues. This phenomenon is addressed as the "leak in the pipeline" [1] - fewer females over time advance to careers in academia. Females in academia and many other engineering work-related environments are not the norm - not statistically, nor sociologically. This problem is addressed as the "strength of numbers" emphasizing that the most important strategy is to improve the relative amount of females [2]. The expectation is that this gender imbalance problem will stop when females grow to a critical mass [3]. However, the question still remains on when we will accomplish this? A strategy that could reduce in the long term this gender gap, at least within academia, is getting female undergraduate students involved early in research projects [1].

Empirical studies make an attempt to (1) understand the decision-making behind female career choices [4-5], (2) pressures that contribute for females to take career breaks [6], (3) factors that have an effect on females in tenure-track positions [7], and (4) overall barriers for female advancement in STEM [8]. While many factors seem to converge, the literature attempts to define the influence of specific domains (e.g. computer engineering [9]), environments (e.g. 
predominately white institutions [10]), ethnicities (e.g. Hispanics [11]) and countries (e.g. Turkey [12]). The results of these efforts include the development of policies to increase recruitment and retention of females as both students and professors [5-6].

After reviewing numerous studies and finding more evidence on the slow advancement of females in STEM fields, this paper addresses the need for new and innovative methods. Therefore, a generalized conceptual model is proposed as a technique to promote complexity thinking in addressing critical factors for females in STEM. Complexity thinking is a less structured thought process that enables creativity and innovation in the design process. Design thinking is usually used as the problem-solving approach to implement systems and complexity thinking. Design thinking celebrates creativity through visual representations [9]. These depictions can summarize large amounts of information, facilitates the recognition of relationships, embraces brainstorming for the development of solutions, and standardizes procedures and terminology [9].

The development of conceptual models, also known as "mind models", is a creative process that is very dependent on its creator. Even with a defined foundation for this research, that is, an extensive literature review, the result can be very subjective. This paper addresses this issue with the development of the model from two perceptions - an undergraduate student and a tenure-track professor. The proposed model results from the combination of the two perceptions. A case study shows the applicability of the conceptual model with a final version generated. This study is based on data from an ADVANCE program in a minority-serving institution.

\section{Literature Review}

\section{A. Empirical studies}

In a literature review on 45 papers, 19 were selected for an in-depth study. These studies implemented different data collection techniques and looked at a diverse range of populations. Interviews were the predominant data collection technique $[5,7,9,11,13]$, while other techniques included: surveys [5, 12, 14-15], focus groups [10, 12], websites [7, 9], and other reports. Some of the reports involve the National Study of Postsecondary Faculty [16-17], the Integrated Postsecondary Data System (IPEDS) [15], and NSF Annual Reports [7].

For the most part, studies were conducted within the Unites States and within one particular institution. Some authors provide a more robust evaluation with the assessment of multiple institutions [7, 14, 18-19]. Also, specific countries are addressed with the study of female's conditions at the United Arab Emirates [5], Qatar [20], and Turkey [12]. Female issues are presented at general domains (STEM, engineering) and specific fields (Industrial Engineering [13], Electrical and Computer Engineering [9], and Civil Engineering [19]). At the same time, some studies address particular ethnicities and environments, such as Hispanic woman [11] and females of color in predominately white institutions [10].

The results from empirical studies can be summarized as the study of the implications for recruitment, retention, and progression. Recruitment issues are addressed from the decisionmaking of career choices to the selection of an academic career [4-5, 12, 13, 18]. Retention 
issues are specified explicitly as the key issues that contribute to females taking career breaks [6], the factors leading to students switching out of STEM [14], and gendered divisions of labor for faculty [16 - 17]. With many similarities between retention and progression issues, specific factors that affect females in tenure-track positions are addressed $[7,16]$. Conclusively, authors end their analysis with the proposition of policies that would help solve the identified recruitment, retention, and progression issues [5-6, 21].

From the overall discussions, two topics seem to lack discussion - the categorization of factors that impact females in STEM and the particular case of female faculty taking career breaks. Trenor [22] defined attrition factors as personal/individual, institutional, and sociocultural. Meanwhile, Sandberg [23] defined factors, as internal and institutional barriers based on the level of control females have to overcome them. Sandberg [23] summarizes institutional barriers as discrimination, sexism, and stereotypes. These are causations for opportunities not to be granted or offered because of the race or gender. Solutions to this problem involve having more females in leadership positions. However, females' internal barriers (or personal/individual factors) impact females' capabilities to advance to leadership positions. This dilemma is what Sandberg [23] calls the "ultimate chicken-and-egg situation."

Internal barriers include the traditional role of females, which involve doing most of the housework and childcare, making space for partners and children that may not exist, and following family and friends' advice to prioritize marriage over career [23]. While females might be able to control some of these factors, females cannot control biology. Those females who had the potential to lead change find themselves taking a career break because could not manage two full-time jobs - a career that requires the "maximum time investment" and the biology that demanded children [23].

For the most part, females leave their jobs after a pregnancy to take care of children, while other circumstances include a partner relocating for work and taking care of an elder family member [6]. When this happens, females feel that they have no other choice. While they feel satisfied with their decision, they face isolation and disconnect from their career during the break, such that returning to the workplace seems challenging [6]. Additional issues females face is fear and lack of self-confidence in their skills to prepare teaching and research statements and negotiate salaries and start-up packages [6].

\section{B. Females in Engineering}

A question that may come to mind is: Why among all STEM fields highlight engineering? The answer is simple. ASEE's report Engineering by the Numbers [24] depicts an alarming low representation of females across all levels-bachelor's level all the way to tenure-track positions in academia. Between 2008 and 2017, females earned 20.93\%, on average, of all engineering degrees (BS, MS, and PhD) in the US (Puerto Rico included) [24]. In 2017 alone, females represented 26,514 out of the 124,477 (21.3\%) undergraduate engineering degrees conferred. Environmental and Biomedical Engineering correspond to the only two programs, in 2017, where females earned more than $37 \%$ of the degrees conferred [24]. Other engineering programs showing a statistically significant improvement over the $20.93 \%$ national average in 2017 are: 
Biological \& Agricultural, Industrial/Mfg./Systems, Chemical Metallurgical \& Materials, Civil/Environmental, Engineering Management, Architectural, Civil, and Engineering (General).

Figure 1 describes the proportion of female-earned degrees and female-filled positions in academia. This graph clearly highlights the lack of the inclusion of females in the field. Despite the low participation of females, in general, the data shows a positive trend for both femaleearned degrees and female-filled tenure-track positions between the years 2008 and 2017. The greatest improvement over time is for tenure-track positions filled, for which there is a percentage difference of $20 \%$ (calculated using Equation 1) in the period. The proportion of female-earned degrees has increased at a slower pace with percentage differences that fluctuate between $12 \%$ and $16 \%$. When considering the proportion of degrees females earned at each level, there is a statistically significant improvement going from BS to MS degrees $(p-v a l<$ $\left.2.2 \times 10^{-16}\right)$. There is, on the other hand, a statistically significant decrease when going from MS to $\mathrm{PhD}$ degrees; nonetheless, the proportion of female-earned $\mathrm{PhD}$ degrees at the $\mathrm{PhD}$ level still represents an improvement over BS degrees $\left(p-\right.$ vals $\left.<2.2 \times 10^{-16}\right)$. In general, the data in Figure 1 helps us conclude that strategies aimed at increasing female participation in engineering might be working, but at a slow pace.

$$
\text { Percentage difference }=100 \times \frac{\left|x_{1}-x_{2}\right|}{0.5\left(x_{1}+x_{2}\right)}
$$

Equation 1
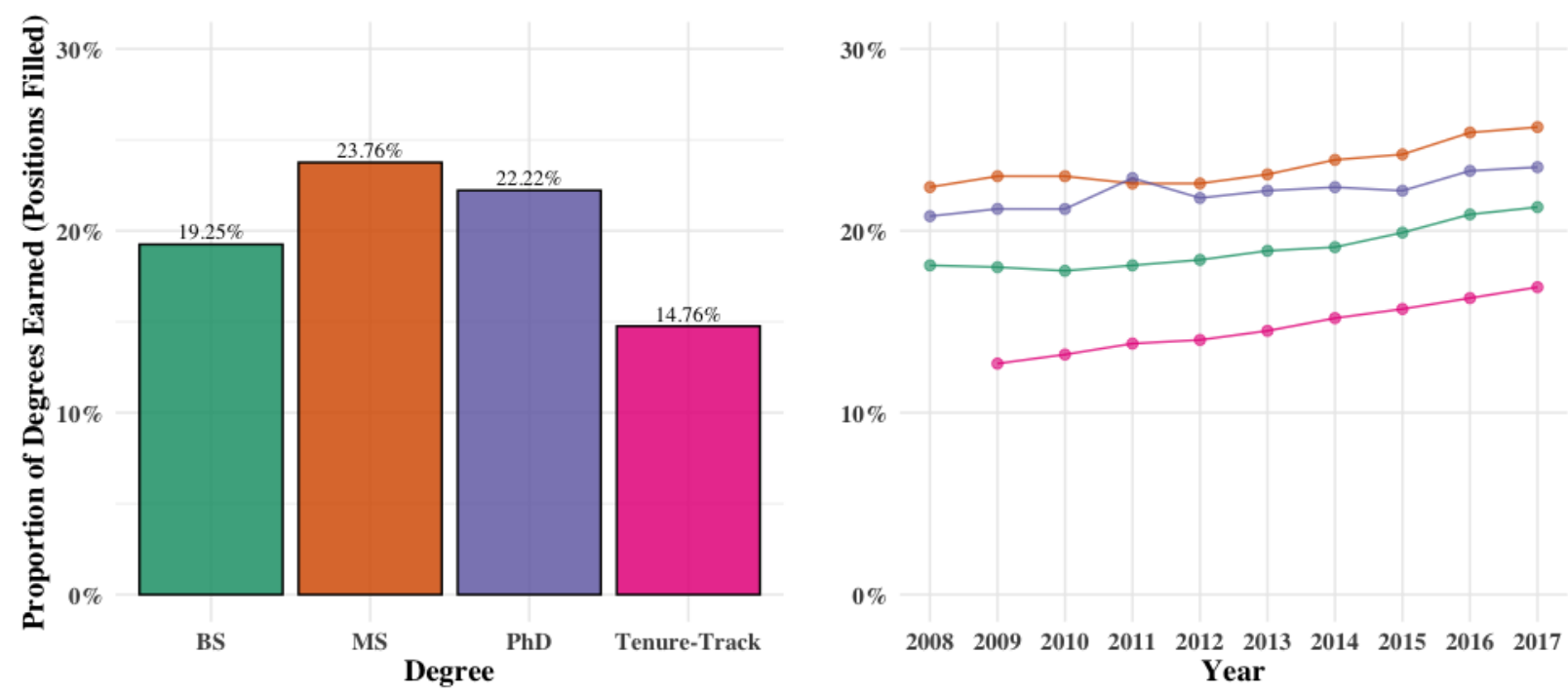

$\square$ BS $\square$ MS $\square$ PhD $\square$ Tenure-Track

Figure 1. Proportion of degrees earned, and tenure-track positions filled.

Data source: (1) Roy, J., Yoder, B. "Engineering by the Numbers,” ASEE, 2017-2018.

Figure 2 shows the type of academic positions filled by females. Unfortunately, this graph shows the phenomenon known as "leak in the pipeline." There is clearly a disparity in the ranks of female faculty. Female representation gets smaller and smaller as the ranks go from Assistant Professor to Full Professor. The amount of female faculty is known to be a factor that positively correlates with the recruitment of females at all levels, as these faculty members often serve as female role models and mentors. As the data shows, most of the female faculty that students are exposed to are likely to be starting their careers in academia, as only $1.44 \%$ of all female 
professors hold a rank of Full Professor. There is a $29 \%$ reduction when it comes to promote female faculty members from Assistant Professor to Associate Professor. Also, there is a further $55 \%$ reduction when it comes to promote female faculty members from Associate Professor to Full Professor. Even more alarming is the $81 \%$ reduction observed between the women that join academia at the rank of Assistant Professor and those who make it to the rank of Full Professor.

Figure 3 further highlights the disparity between males and females along with a characterization of female race. Needless, to say there is a statistically significant disparity between female and male representation in academia $\left(p-v a l<2.2 \times 10^{-16}\right)$. Male representation is almost six times larger than female representation and, while the gap is slowly decreasing, the overall female participation in academic roles simply improved by 5\% between 2009 and 2017 . Out of the outstandingly low $14.76 \%$ of all tenure-track positions that are filled by females, only $4.7 \%$ of these correspond to females of color. This fact makes it extremely hard for females in these minority groups to be exposed to female role models they can relate to.

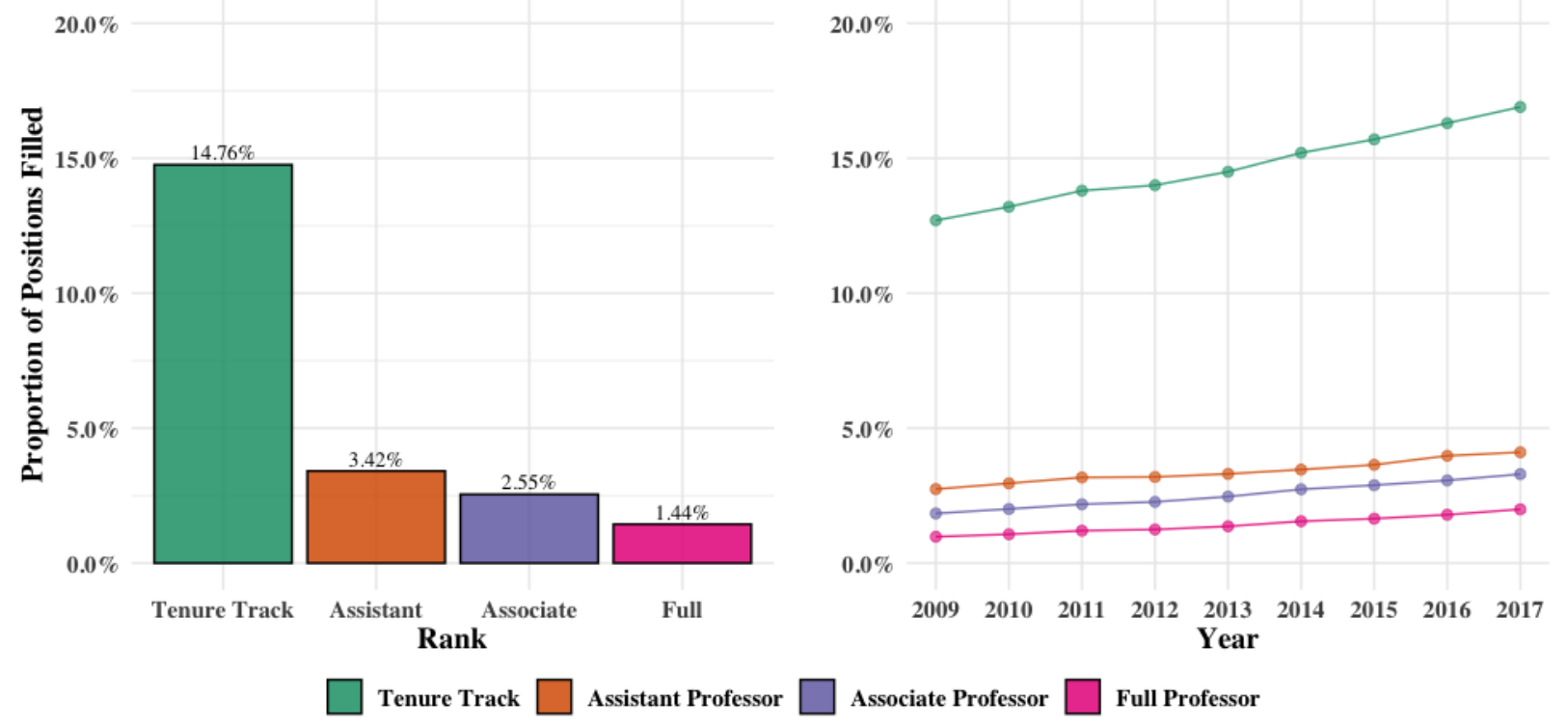

Figure 2. Proportion of academic positions filled by rank.

Data source: (1) Roy, J., Yoder, B. "Engineering by the Numbers,” ASEE, 2017-2018.

\section{Conceptual models}

Among all the articles of relevance to this work, Trenor [22] was the only effort to develop a conceptual model of the issue's females face in STEM. The model is defined as the females in engineering pipeline. It uses a pipeline as an analogy to represent the flow of female students into STEM careers with the input of "not enough inflow of female students" and the question of "how can we attract more young females into engineering?" [22]. Throughout the pipeline, arrows are shown as leakages from the system. These leakages refer to specific factors: uniformed choices, poor academic preparation, feeling of isolation, "chilly" classroom climate, and poor math/science/engineering self-efficacy [22]. These factors bring up the question of how can we retain more females in engineering majors? [22]. Finally, the outcome of the whole pipeline is "not enough outflow of female students" which leads to the question of "how can we 
retain more females in the engineering workforce?" While Trenor [22] addresses important recruitment and retention issues, many other retention factors were identified in the literature. The work presented herein intends to bridge this gap in the literature by developing a generalized and comprehensive conceptual model of critical factors for females in STEM.

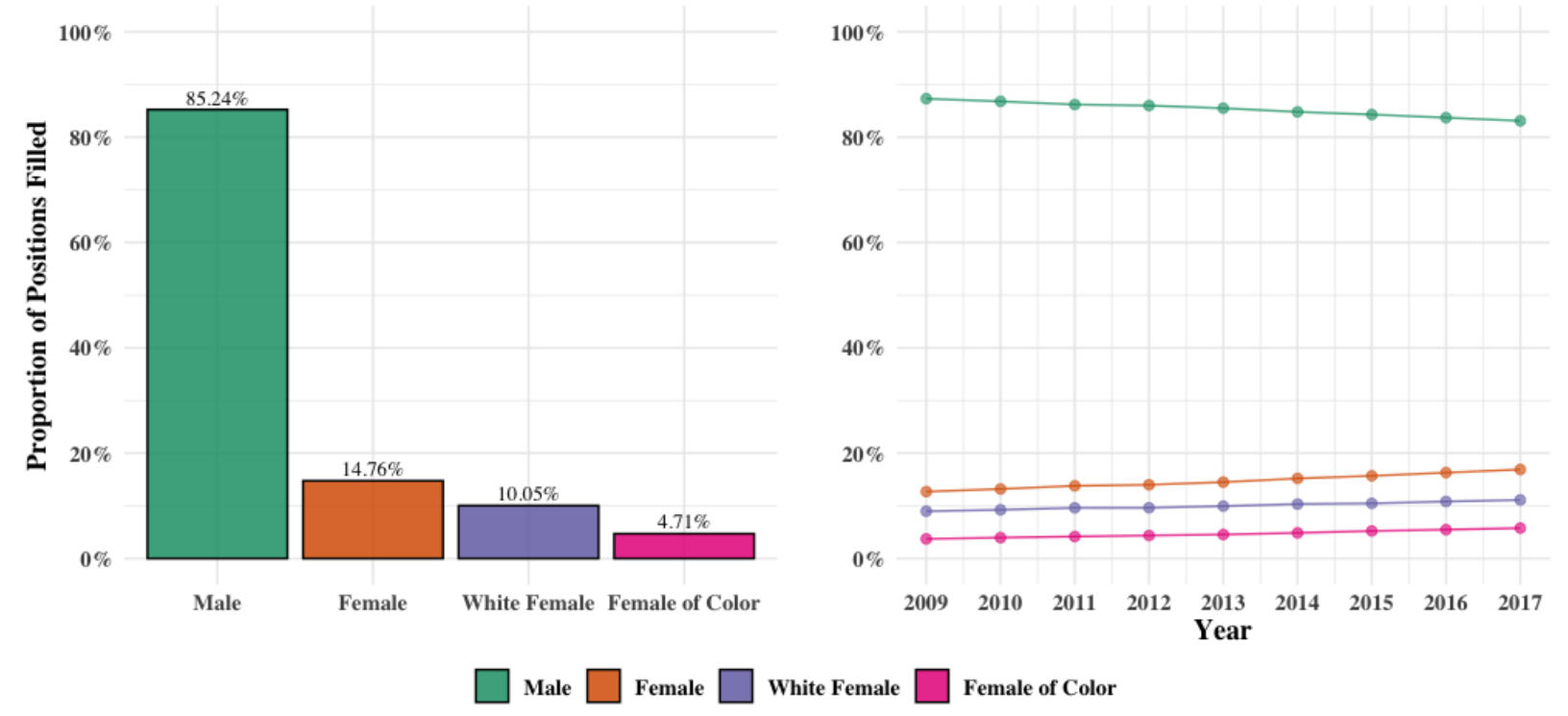

Figure 3. Proportion of positions filled by gender and race.

Data source: (1) Roy, J., Yoder, B. "Engineering by the Numbers," ASEE, 2017-2018.

\section{Methodology}

The previous discussion sheds light on the different factors that affect female's recruitment, retention, and overall difficulties to progress in STEM fields. While these factors are diverse, the convergence between studies is considered in the development of the conceptual model. Figure 4 provides an outline of the process followed with three major phases: identification of factors, development of conceptual model, and a case study of model relevance.
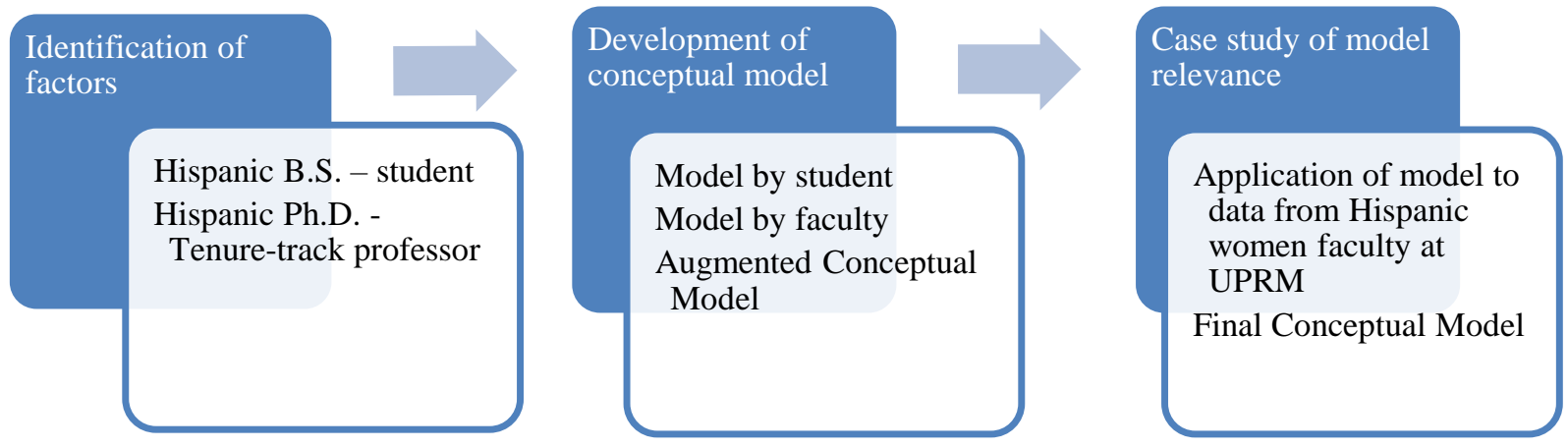

Figure 4. Methodology steps.

Creating a succinct list of factors that impact female advancement in STEM maintains some subjectivity even with a strong framework. The development of "conceptual models" or "mind 
models" is considered a creative process that is very dependent on the creator. This paper addresses this issue with the development of the model from two perceptions - an undergraduate student and a tenure-track professor. For consistency, both creators were provided with the same set of forty-five papers to review. However, the rest of the procedure was completely unstructured with the objective of not adding any burdens into the creative process. The proposed model results from the combination of these two perceptions. A case study shows the applicability of the augmented conceptual model while generating a final version. This study is based on data from an ADVANCE program performed at a minority-serving institution.

\section{Discussion of Results}

\section{A. Perception of a female and Hispanic undergraduate student}

The undergraduate student reviewed the literature and highlighted the relevance of factors in terms of their frequency of occurrence (Figure 5). As a result of her analysis, she generated a conceptual model of three parts: cultural, "lack of interest," and retention. The most frequent factors in Figure 5 include the differences by gender, traditional role of females in relation to family and motherhood, and negative stereotypes. These factors are characterized in the model, as related to the culture in which females are raised. Male predominance has affected how females react and, therefore, it affects female career choices. Traditionally, males were the providers in the household. Females had to stay at home taking care of children. These "traditional" roles created stereotypes that made it difficult for females to aspire to a career in particular fields, such as engineering that was defined and generalized as a male-dominated field. Religion and social issues support the idea of "jobs for males" and "jobs for females." The lack of social support could lead to low self-esteem for females in comparison to their male counterparts.

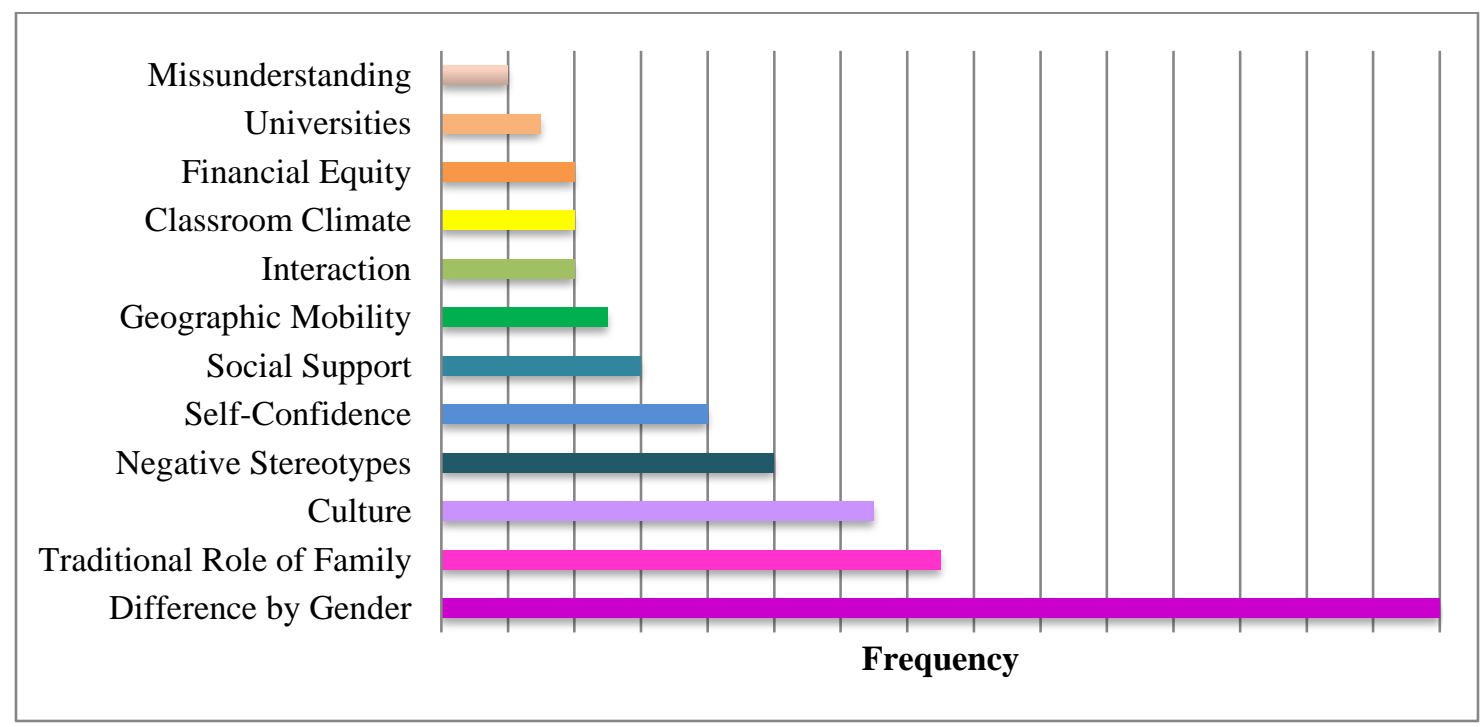

Figure 5. Frequency of factors for females in STEM.

Some factors are specifically related to females" "lack-of-interest." The information that universities disseminate does not promote that STEM careers are for all genders. In addition, 
there is a generalized misunderstanding of what a career in engineering entitles. From a retention point of view, the undergraduate student defined various factors that make females abandon STEM careers and their selection. Classroom environment is not welcoming; females are mostly feeling stressed and pressured. For example, females feel pressured by their male counterparts. Also, the lack of interaction with female faculty and student peers has a negative effect on females' retention. In general, female's academic competency and females' salaries (for financial equity) are lower in comparison to males. Furthermore, female retention is affected by geographic mobility. Due to females' role with family and children, they do not likely to risk being away from family for work.

\section{B. Perception of a female and Hispanic tenure-track professor}

The tenure-track professor started reviewing the forty-five articles and separated the ones with empirical studies. The summary of factors per empirical study was reviewed following Trenor [22] and Sandberg [23] classification of factors. Therefore, the analysis included the following categories: personal/individual, institutional, external, and sociocultural. Both, personal/individual and institutional factors represent the larger component of the conceptual model proposed.

The personal/individual category involved a definition of factors that are intrinsic to the individual or influencing factors from their particular environment-community, papers, and teachers. A hierarchical framework is provided to explain categories, subcategories, and their relationships. For example, the strength of career orientation is shown in the model to have influence from the community, parents, and teachers. The reason for this is that, in cases in which the career orientation strength is weak, females may still select a STEM field due to the community/parental/teacher influence that encourages them because they have a good performance in math and science. The contrary is also true. Females with strong career orientation may be discouraged by the same set of influencing people.

Four main institutional factors are defined to impact females in STEM fields. These are: number of female faculty, culture, salary, and tenure-track procedures. The number of female faculty mostly impacts the number of role models and mentors, faculty-student interactions, and the number of females in leadership positions. The institutional culture is related to the feel of isolation and collegiality, the support and practices from leadership positions, and the policies to help or discriminate against females. The salary is included as an institutional factor, given the common practice of paying lower salaries to females. In addition, tenure-track processes are not welcoming with a low number of development opportunities for females.

Finally, a small subset of factors is included as external and sociocultural factors. External factors refer to the support from agencies, such as the National Science Foundation (NSF), to improve female's recruitment, retention, and progression in STEM fields. NSF values diversity, considering this in the broader impact of every proposal and having programs dedicated to this objective (e.g. ADVANCE programs). External factors also include a network of peer institutions. Meanwhile, sociocultural factors are focused on discrimination, stereotypes, and prejudice that force females to make a greater effort to gain credibility and respect, being assigned the less-preferred tasks and having a lower valuation of their work for tenure and merit. 


\section{Combination of models}

In combining the two models, the most robust model was selected as a starting point. The model developed by the tenure-track professor was deemed more robust given her prior research experience. Even so, the model was not complete, as it did not account for some of the factors identified by the undergraduate student. As a result, the following factors were added: religion as a sociocultural factor and public/private university from the culture of institutional factors. Other factors in the original model were summarized, as is merging career orientation strength and commitment into a single factor. Awareness of career options was eliminated, and selfperception, self-concept, self-confidence, and fear were consolidated into one factor.

The different factors were further analyzed in two different criteria based on the literature review -their positive or negative impact on females and their relevance to female's recruitment, retention, and progression. Within each factor definition a plus (+), minus (-) or plus/minus (+/-) sign was included to further illustrate whether the factor has a positive effect, a negative effect, or its effect will depend on the specific scenario under consideration. In addition, a color-coded framework was used to identify if the factor could impact recruitment (red), retention (green), or progression (ivory). When the impact was for two of these criteria, a pattern with the two corresponding colors was used. The results from these adjustments are in Figure 6.

\section{Case study of Hispanic female faculty at a minority-serving institution}

A scenario is evaluated to show the relevance of the proposed conceptual model to the case of Hispanic females' faculty at the minority-serving institution. The data from this scenario was not considered in the creation of the conceptual models. This case study is based on the results from an NSF ADVANCE program performed at a minority-serving institution during the years 20082010 [25-26]. It had the objective of defining the barriers that influence females in their pursuit of academic careers and progression into higher ranks [25]. The authors of this work indicated that to the best of their knowledge, there were no previous works at the time that addressed gender inequality and institutional climate for an institution with characteristics similar to those of the minority-serving institution [25]. For the scope of this paper, two poster reports [25-26] were evaluated to identify their most relevant results in relation to the conceptual model.

\section{D.1 Why focus on a case study at a minority-serving institution?}

The minority-serving institution selected can be considered a somewhat unusual institution within the American education system. It is a medium-sized public institution with an average enrollment of nearly 12,500 undergraduate students, 900 graduate students, and an average yearly admission rate of 2,150 students. More than $99 \%$ of the student population is of Hispanic origin and, among all institutions within the US, the selected institution has the largest number of faculty members of Hispanic origin [28]. The minority-serving institution used for this study offers bachelor's degrees all the way to $\mathrm{PhD}$ degrees, including occasional postdoctoral opportunities. Admission requirements include a high school diploma, the College Entrance Examination Board Exam (CEEB, Spanish version) or SAT; and a minimum general application index (50\% high-school GPA and 50\% CEEB aptitude tests), which are set for each program. 
As of 2012, the full-time teaching faculty consisted of 250 females and 410 males, for a $38 \%$ of females in traditional faculty roles [29]. Within the School of Engineering and as, of 2013, the percentage of female faculty members was smaller; yet, there was not a statistically significant difference $(p-v a l=0.153)$ with respect to all programs on campus. There were 37 females and 114 males, for a $32.5 \%$ female representation within the full-time teaching faculty across all engineering programs [30]. When we compare this average for the School of Engineering to national average (less than 15\%), there is, nevertheless, a statistically significant improvement $\left(p-v a l=5.418 \times 10^{-9}\right)$ in terms of the participant of females in tenure-track roles. The results for the Advance program case study, that will be discussed in the following section, will show that; although, the selected minority-serving institution is an unusual institution within the American education system, most of the challenges its female faculty members share are fairly similar to the issues that we previously focused on in the literature review.

\section{D.2 Results}

The results from this analysis are summarized in Tables 1 and 2. The summary in Table 1 corresponds to the first report of the Advance program in the year 2009, in which they performed a self-assessment study to identify issues affecting recruitment, retention, and promotion of female faculty in STEM fields [25]. This self-assessment involved the completion of a survey by 40 faculty members that participated at the IV Encuentro - Repensando la Educación, where the project was presented. In addition, they also provide the results from an external evaluator to assess the climate of the institution under study. The evaluator's major findings included lack of awareness of female faculty issues, shortage of female faculty, absence of policies and practices to make "family-friendly" climate, and the need for diversity trainings [25].

Table 1. Summary of relevant results from [25] and relationship with identified factors.

\begin{tabular}{|c|}
\hline Factor \\
\hline $\begin{array}{l}\text { Factor in model: career orientation } \\
\text { strength and commitment, } \\
\text { mentoring }\end{array}$ \\
\hline $\begin{array}{l}\text { Factor in model: advancement } \\
\text { opportunity; } \\
\text { Add factor: geographic location - } \\
\text { family preference, } \\
\text { personal/individual- personal ties }\end{array}$ \\
\hline $\begin{array}{l}\text { Factor in model: research support; } \\
\text { Add factor: salary- start-up } \\
\text { package }\end{array}$ \\
\hline $\begin{array}{l}\text { Add factor: policies to help females } \\
\text { - e.g. care of children, stop the } \\
\text { clock during tenure period, dual } \\
\text { career couples }\end{array}$ \\
\hline $\begin{array}{l}\text { Factor in model: mentoring; } \\
\text { Add factor: department } \\
\text { orientations }\end{array}$ \\
\hline $\begin{array}{l}\text { Factor in model: mentoring; } \\
\text { Add factor: department } \\
\text { orientations, fund doctoral studies, } \\
\text { faculty-student interaction - } \\
\text { undergraduate research, teacher } \\
\text { assistantship }\end{array}$ \\
\hline
\end{tabular}

Question
What did you consider for selecting the academia as a
profession?

What factors did you take into consideration when you applied and accepted to be a faculty member of the minority-serving institution?

What barriers or obstacles interfere with the retention and advancement of professors in your College?

Many universities have programs (i.e. care of children, stop the clock during tenure period, dual career couples, among others) to help female faculty balance family and work. Which is your perception of having these programs available in your department?

Which initiatives would you recommend to interest females in academia and for their employment, retention, and development of leaders?

Which initiatives could be developed to motivate female students to pursue a career in academia?

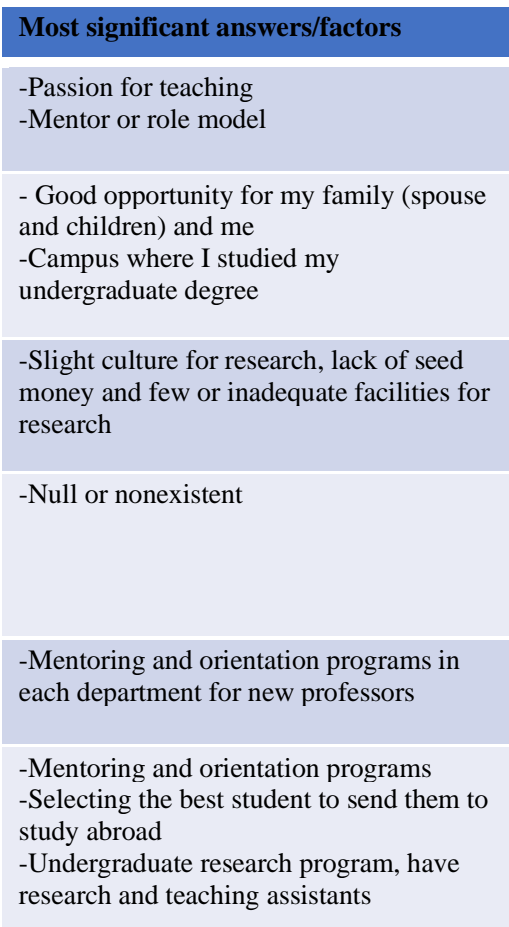


Their second report, summarized in Table 2, provides a more in-depth study with the results from a work climate survey and a reflexive journal [2]. These results were collected at the end of the two-year duration of the project and reported in 2010. This survey involved a greater population with 146 responses including both male and female respondents. In addition, they implemented a semi-structural reflexive journal during a two-day workshop for 33 female professors in STEM that included closed, open-ended, and probing questions [26].

As outcomes from this analysis (refer to Tables 1 and 2), eight factors from the conceptual model ( $27 \%$ of the model) were relevant to females' climate and thirteen new factors ( $55 \%$ increase) were added to the model. The model was revised accordingly, and a newer version was proposed in Figure 7. The eight relevant factors are highlighted with a red square, including the following: career orientation strength and commitment, traditional role of females with a focus on women raising children, number of role models and mentors, faculty-student interaction, research support, advancement opportunities, and task assignment.

Table 2. Summary of relevant results from [26] and the relationship with identified factors.

\begin{tabular}{|c|c|c|}
\hline Factor & Question & Answer (M: males, F: females) \\
\hline Factor in model: Mentoring & $\begin{array}{l}\text { Does your department have any formal policy or } \\
\text { mentoring program for new faculty? }\end{array}$ & $\begin{array}{l}\text { - Yes: } 22 \%(58 \% \mathrm{~F}, 42 \% \mathrm{M}) \\
\text { - No: } 55 \%(40 \% \mathrm{~F}, 60 \% \mathrm{M}) \\
\text { - Do not know: } 23 \%(38 \% \mathrm{~F}, 62 \% \mathrm{M})\end{array}$ \\
\hline Factor in model: Mentoring & Do you consider that you received adequate mentoring? & $\begin{array}{l}\text { - Yes: } 27 \%(50 \% \text { F, } 50 \% \text { M) } \\
\text { - No: } 33 \%(67 \% \text { F, 33\% M) } \\
\text { - Partially: } 60 \% \text { (37\% F, 63\% M) }\end{array}$ \\
\hline Factor in model: Mentoring & $\begin{array}{l}\text { Do you think it is necessary to establish a formal peer- } \\
\text { mentoring program for new professors? }\end{array}$ & $\begin{array}{l}\text { - Yes: } 72 \%(28 \% \mathrm{~F}, 44 \% \mathrm{M}) \\
\text { - No: } 4 \%(4 \% \mathrm{~F}, 0 \% \mathrm{M})\end{array}$ \\
\hline $\begin{array}{l}\text { Factor in model: Task } \\
\text { assignment }\end{array}$ & $\begin{array}{l}\text { In your opinion and compared to your peers in your } \\
\text { department, how much time do you spend working in } \\
\text { committees (or other services)? }\end{array}$ & $\begin{array}{l}\text { - Less time: } 14 \%(9 \% \mathrm{~F}, 17 \% \mathrm{M})- \\
\text { - Same time: } 28 \%(23 \% \mathrm{~F}, 32 \% \mathrm{M}) \\
\text { - More time: } 58 \%(68 \% \mathrm{~F}, 51 \% \mathrm{M})\end{array}$ \\
\hline $\begin{array}{l}\text { Factor in model: Traditional role } \\
\text { of females/ priorities }\end{array}$ & $\begin{array}{l}\text { Sources of stress during the past } 12 \text { months - managing } \\
\text { home responsibilities }\end{array}$ & $\begin{array}{l}\text { - Much stress: } 26 \% \text { of females versus } \\
16 \% \text { of men. }\end{array}$ \\
\hline $\begin{array}{l}\text { Factor in model: Raising } \\
\text { children }\end{array}$ & Sources of stress during the past 12 months - childcare & $\begin{array}{l}\text { - Much stress: } 11 \% \text { of females versus } 7 \% \\
\text { of men. }\end{array}$ \\
\hline $\begin{array}{l}\text { Add factor: Personal/ individual } \\
\text { - health }\end{array}$ & Sources of stress during the past 12 months - health & $\begin{array}{l}\text { - Much stress: } 18 \% \text { of females versus } 8 \% \\
\text { of men }\end{array}$ \\
\hline $\begin{array}{l}\text { Add factor: Sociocultural - Cost } \\
\text { of living }\end{array}$ & $\begin{array}{l}\text { Sources of stress during the past } 12 \text { months - cost of } \\
\text { living }\end{array}$ & $\begin{array}{l}\text { - Much stress: } 45 \% \text { of females versus } \\
26 \% \text { of men }\end{array}$ \\
\hline $\begin{array}{l}\text { Add factor: Job duties and } \\
\text { tenure-track processes } \\
\text { - Scholarly productivity }\end{array}$ & $\begin{array}{l}\text { Sources of stress during the past } 12 \text { months - scholarly } \\
\text { productivity }\end{array}$ & $\begin{array}{l}\text { - Much stress: } 48 \% \text { of females versus } \\
35 \% \text { of men }\end{array}$ \\
\hline $\begin{array}{l}\text { Add factor: Job duties and } \\
\text { tenure-track processes } \\
\text { - Teaching responsibilities }\end{array}$ & $\begin{array}{l}\text { Sources of stress during the past } 12 \text { months - teaching } \\
\text { responsibilities }\end{array}$ & $\begin{array}{l}\text { - Much stress: } 44 \% \text { of females versus } \\
29 \% \text { of men }\end{array}$ \\
\hline $\begin{array}{l}\text { Factor in model: Task } \\
\text { assignment }\end{array}$ & $\begin{array}{l}\text { Sources of stress during the past } 12 \text { months - } \\
\text { committee or administrative review process }\end{array}$ & $\begin{array}{l}\text { - Much stress: } 44 \% \text { of females versus } \\
28 \% \text { of men }\end{array}$ \\
\hline
\end{tabular}




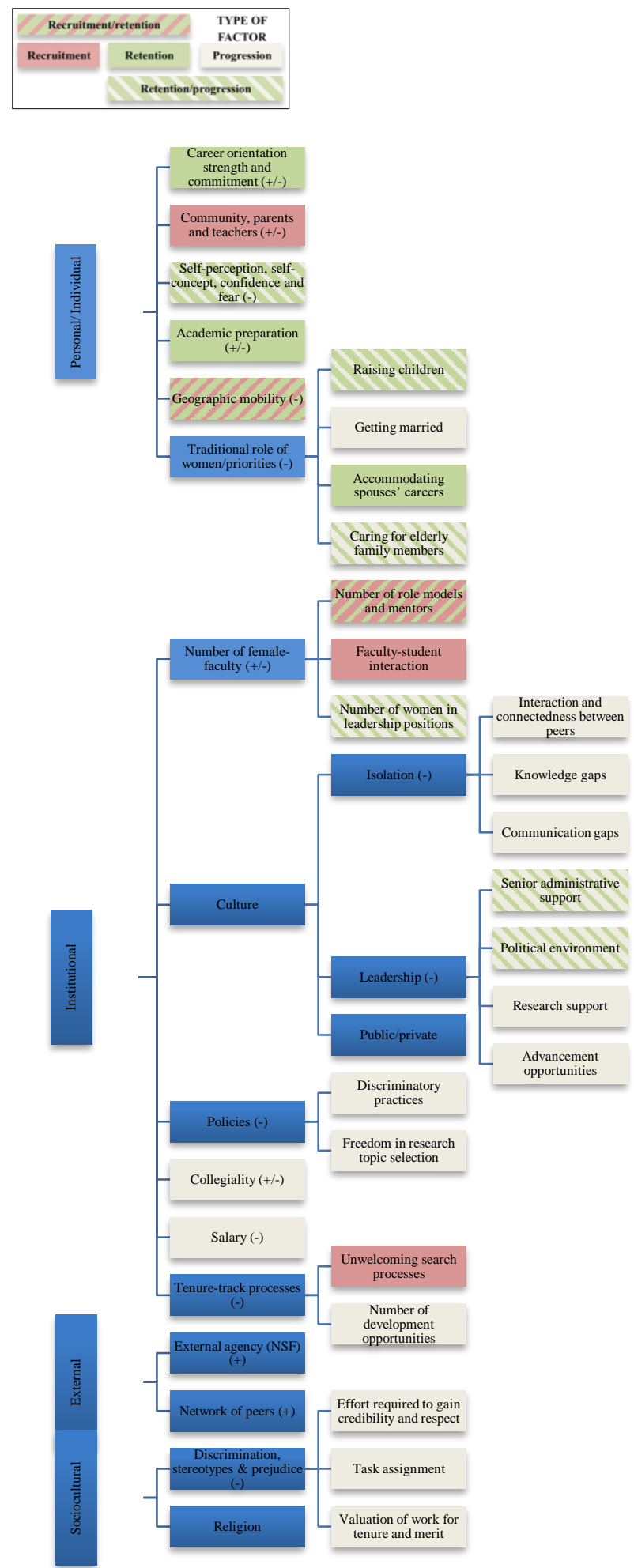

Figure 6. Critical factors for females in STEM based on their positive (+) or negative (-) impact and the relationship with females' recruitment, retention, and progression.

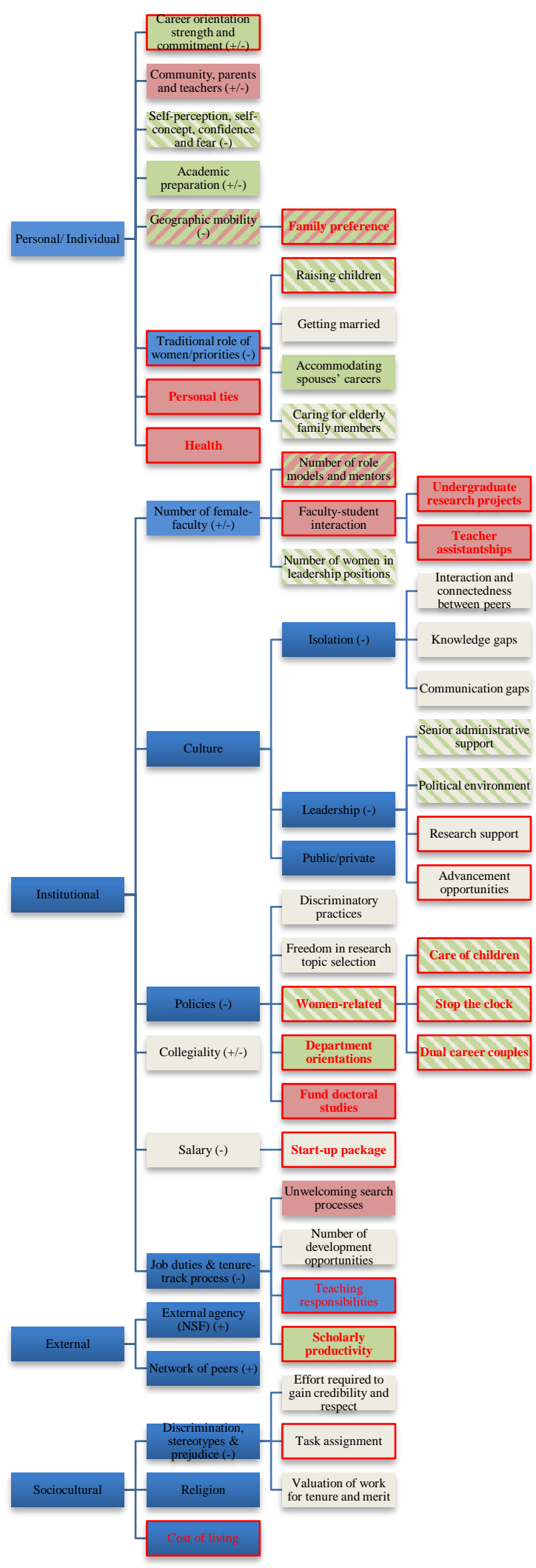

Figure 7. Final Conceptual Model. 
Thirteen new factors are highlighted with a red square and bold red letters. These factors are: family preference of geographic location, personal ties, health, undergraduate research projects, teacher assistantships, females-related policies (care of children, stop the clock, and dual-career couples), department orientations, funding doctoral studies, start-up package, teaching responsibilities, scholarly productivity, and cost of living. Factors at most levels were addressed, with most relevance to personal/individual factors, institutional factors, and sociocultural factors.

The results from the minority-serving institution's ADVANCE program are consistent with the reviewed literature in terms of the relevance given to mentoring as a key factor for female's recruitment, retention, and progression. Meanwhile, the traditional role of females is not highlighted as a particularly relevant factor, given the fact that females have higher responsibility raising children and need non-existent policies at the minority-serving institution to facilitate this role. The greater number of issues addressed were related to institutional factors, which was within the major scope of the ADVANCE program.

\section{Conclusions and Future Work}

A conceptual model was developed to promote complexity thinking when solving critical factors for females in STEM. The model, with a total of fifty-five issues divided into four main hierarchical levels, provides an organized and simplified framework for the comprehensive study of recruitment, retention, and progression issues for females in STEM. A case study, with data not considered in the model development, showed the significance of a portion of the factors and proposed the addition of other factors. Females that are either undergraduate/graduate students or tenure-track faculty can benefit from the proposed model to understand the factors that they need to deal with, in order to improve their chances of success. While it being far from the ideal scenario, females must work around institutional barriers. Attesting to this, Sandberg [23] provides some scenarios in which females should act intelligently to advance in their careers. Some of these strategies include looking at the career as a jungle gym, finding a mentor, seeking and speaking the truth, and making the partner a real partner, among others [23].

With this paper, institutions are invited to use the proposed model in their institutional decisionmaking processes and as a method to find solutions to female-specific issues. Future research directions have the potential to advance this work. The logical follow-up to this work would be to evaluate the applicability of the revised model in a non-Hispanic-serving institution. A conceptual model of critical factors for males in the workplace would also provide an interesting comparison to the model presented here. Meanwhile, the model presented for females can be analyzed further from the point of view of a focus group or by using a weighted scheme for the different factors. Last but not least, the study of specific scenarios, such as breastfeeding, could unfold additional challenges. 


\section{References}

[1] W. Tyson and K. Borman, "Perceived department culture among tenured female faculty in sciences and engineering," in American Sociological Association Annual Meeting, San Francisco, CA, 2009.

[2] V. A. Lagesen, "The strength of numbers strategies to include females into computer science. In Social Studies of Science, vol. 37, no. 1, pp. 67-92, 2007

[3] R. M. Kanter, Men and Females of the Corporation. $2^{\text {nd }}$ ed., New York: Basic Books, 1993.

[4] J.S. Eccles, "Understanding females's educational and occupational choices," in Psychology of Females Quarterly, vol. 18, pp. 585-609, 1994.

[5] N. G. Aswad, G. Vidican and D. Samulewicz, "Creating a knowledge-based economy in the United Arab Emirates: realising the unfulfilled potential of females in the science, technology and engineering fields," in European Journal of Engineering Education, vol. 36, no. 6, pp. 559 - 570, 2011.

[6] C. Mavriplis, R. Heller, C. Beil, K. Dam, N. Yassinskaya, M. Shaw and C. Sorensen, "Mind the Gap: Females in STEM career breaks," in Journal of Technology Management \& Innovation, vol. 5, no. 1, pp.140-151, 2010.

[7] D. Bilimoria, S. Joy and Xiangfen Liang, "Breaking barriers and creating inclusiveness: Lessons of organizational transformation to advance females faculty in academic science and engineering," Human Resource Management, vol. 47, no. 3, pp. 423-441, 2008.

[8] V. Valian, Why so slow? The advancement of females. Cambridge, MA: The MIT Press, 1999.

[9] A. Assimaki, G. Koustourakis and K. Papaspyropoulou, "Female faculty members in the field of electrical and computer engineering: The case of greek universities," Problems in Education in the 21st Century, vol. 39, 2012.

[10] C.S.V. Turner, J.C. González, K. Wong, "Faculty females of color: The critical nexus of race and gender", in Journal of Diversity in Higher Education, vol. 4, no. 4, pp. 199-211, 2011.

[11] J.P. Martin, D.R. Simmons and S.L. Yuc, "The role of social capital in the experiences of Hispanic females engineering majors." in Journal of Engineering Education, vol. 102, no. 2, pp. 227-243, 2013.

[12] A.E. Smitha and B. Dengizb, "Females in engineering in Turkey - a large scale quantitative and qualitative examination," in European Journal of Engineering Education, vol. 35, no. 1, pp. 45-57, 2010.

[13] B.J. Harris, T.R. Rhoads, S.E. Walden, T.J. Murphy, R. Meissler and A. Reynolds, "Gender equity in Industrial Engineering: A pilot study, in NWSA Journal, vol. 16, no. 1, 2004.

[14]E. Seymour and N.C. Hewitt. Talking About Leaving: Why Undergraduates Leave the Sciences. Boulder, CO: Westview Press, 1997.

[15] G. Sonnert, M.F. Fox and K. Adkins, "Undergraduate females in science and engineering: Effects of faculty, fields, and institutions over time," Social Science Quarterly, vol. 88, no. 5, 2007.

[16]C. Carrigan, K. Quinn, E.A. Riskin, "The gendered division of labor among STEM faculty and the effects of critical mass," in Journal of Diversity in Higher Education, vol. 4, no. 3, pp. 131-146, 2011.

[17] Y.J. Xu, "Gender disparity in STEM disciplines: A study of faculty attrition and turnover intentions," in Research in Higher Education, vol. 49, no. 7, pp. 607-624, 2008. 
[18] B.J. Canes and H.S. Rosen, "Following in her footsteps? Females's choices of college majors and faculty gender composition," in Industrial and Labor Relations Review, vol. 48, no. 3, pp., 1995.

[19] K.M. Leonard and G.M. Nicholls, "History and status of female faculty in civil engineering", in Journal of Professional Issues in Engineering Education and Practice, vol. 139, no. 3, pp. 218-225, 2013.

[20] N.F. Sulaiman and H. AlMuftah, "A Qatari perspective on females in the engineering pipeline: An exploratory study," in European Journal of Engineering Education, vol. 35, no. 5, pp. 507-517, 2010.

[21] J.E. Mills, "Reflections on the past, present and future of females in engineering," in Australasian Journal of Engineering Education, vol. 17, no. 3, pp. 139-145, 2011.

[22] J.M. Trenor, (2007). Advancing the females in engineering pipeline: What you can do to help recruit and retain female undergraduates. [Online]. Available: http://www.eweek.org/site/News/Eweek/2007_marathon/Trenor

[23] S. Sandberg, S., Lean In: Females, Work, and the Will to Lead. $1^{\text {st }}$ ed., New York: Random House, Inc., 2013.

[24] B. L. Yoder, "Engineering by the numbers," American Society for Engineering Education, 2017. [Online] Available: https://www.asee.org/../2017-Engineering-by-Numbers-Engineering- Statistics.pdf

[25] M. Chaparro, S.M. Bartolomei-Suárez, L. Guillemard, CoPI, M. Vera, A. Cruz-Pol, A. González-Quevedo, and L. Marrero, "A Self-assessment study to identify issues affecting recruitment, retention and promotion of females faculty in STEM fields," Minority-serving institution.

[26] M. Chaparro, S.M. Bartolomei-Suárez, L. Guillemard, CoPI, M. Vera, A. Cruz-Pol, A. González-Quevedo, and L. Marrero, "Results from the work climate survey and the reflexive journal," Minority-serving institution, 2010.

[27] OIIP, Minority-serving institution "Statistical Reports," 2015. [Online]. [Accessed: 17-Feb-2015].

[28] OIIP, Minority-serving institution “Teaching Personnel," Statistical Data on Teaching and Non-Teaching Personnel. [Online]. [Accessed: 17-Feb-2015].

[29] ASEE, "Institutional Profile of University of Puerto Rico, Mayaguez Campus," 2013. [Online]. Available: http://profiles.asee.org/profiles/6045/print_all. [Accessed: 16-Feb-2015]. 